\title{
Co-Creation of a Working Model to Improve Sexual Health for Persons Living with Rheumatological Diseases
}

\author{
Kristina Areskoug-Josefsson 1,2,3*, Sara Hjalmarsson"4, Mathilda Björk5,6, Annette Sverker ${ }^{7}$ \\ ${ }^{1}$ School of Health and Welfare, The Jönköping Academy for Improvement of Health and Welfare, Jönköping University, \\ Jönköping, Sweden \\ ${ }^{2}$ Department of Behavioural Sciences, Faculty of Health Sciences, Oslo Metropolitan University, Oslo, Norway \\ ${ }^{3}$ Faculty of Health Studies, VID Specialized University, Sandnes, Norway \\ ${ }^{4}$ Swedish Rheumatism Association, Norrköping, Sweden \\ ${ }^{5}$ Division of Occupational Therapy, Department of Social and Welfare Studies, Faculty of Health Sciences, Linköping University, \\ Linköping, Sweden \\ ${ }^{6}$ Department of Rheumatology, Heart and Medicine Center, Region Östergötland, Sweden \\ ${ }^{7}$ Department of Activity and Health, Department of Rehabilitation Medicine and Department of Medical and Health Sciences, \\ Linköping University, Linköping, Sweden \\ Email: *kristina.areskoug-josefsson@ju.se
}

How to cite this paper: Areskoug-Josefsson, K., Hjalmarsson, S., Björk, M. and Sverker, A. (2020) Co-Creation of a Working Model to Improve Sexual Health for Persons Living with Rheumatological Diseases. Open Journal of Rheumatology and Autoimmune Diseases, 10, 109-124. https://doi.org/10.4236/ojra.2020.103013

Received: May 5, 2020

Accepted: June 6, 2020

Published: June 9, 2020

Copyright () 2020 by author(s) and Scientific Research Publishing Inc. This work is licensed under the Creative Commons Attribution-NonCommercial International License (CC BY-NC 4.0). http://creativecommons.org/licenses/by-nc/4.0/ (c) (i) \&) Open Access

\begin{abstract}
Background: Sexual health needs are insufficiently met for persons living with rheumatological diseases and it is necessary to create better ways to meet these needs. Objective: To co-create a working model to improve sexual health for persons living with rheumatological diseases, that can be used by rheumatological teams in regular rheumatology practice. Design: This study applied a co-creation design with three key features: 1 ) it took a systems perspective with emergent multiple interactive entities; 2 ) the research process was viewed as a creative endeavour with strong links to design, while human imagination and the individual experience of patient and staff were at the core of the creative design effort; 3 ) the process of the co-creative efforts was as important as the generated product. Results: A model defining the role of the patient, the professionals, and the team in optimizing sexual health for persons living with rheumatological diseases was co-created. The model can be seen as a practice guideline, which includes the support needed from and to each participant in the process of promoting sexual health, while being within the professional scope of the professionals' knowledge and capacity, and in line with the needs of the persons living with rheumatological diseases. Discussion and Conclusions: The co-creative work process identified crucial factors in promoting sexual health, resulting in a useful model for patients,
\end{abstract}


professionals and teams. Co-creation was experienced to be a useful research design to improve rheumatological care, through valuing and using the competence of all research members equally.

\section{Keywords}

Co-Creation, Rheumatology, Sexual Health, Sexuality, Care, Sweden

\section{Introduction}

A novel Swedish report by the Swedish Rheumatism Association states that sexual health needs are insufficiently met for persons living with rheumatological diseases and there is a need to create better ways for rheumatological teams to meet this need [1]. One way could be to develop a working model, based on a co creating process, involving both patients and professionals, to be used in the clinical care. Rheumatological diseases often affect sexual health negatively due to disease-related factors, psychological responses to living with the disease and toxic effects of anti-inflammatory and immunosuppressive drugs [2]-[8]. Sexual concerns are prevalent among all genders, and can have significant impacts on mood, quality of life, and self-esteem, as well as causing emotional distress and relational problems [9] [10] [11] [12] [13]. Persons living with rheumatological diseases have reduced family size [2], indicating the importance of reproductive health also being addressed. Gender, social context, culture and physical differences can also influence how diseases are experienced as affecting sexual health [14].

Sexual health is an often neglected topic among health care professionals [2] [15] [16] due to various reasons, including lack of knowledge, competence and time, as well as embarrassment and fear. However, it is important that health professionals understand how sexual health may be affected by various conditions and how to address the concerns and needs of their patients, and previous research in rheumatology has shown that the quality of communication with health care professionals is linked to patient outcomes [17].

Persons living with rheumatological diseases are often cared for by a team consisting of various health care professionals (rheumatologist, nurse, occupational therapist, physiotherapist, social counsellor, assisting nurse), who all need to work together to co-create health services in an equal partnership with patients to achieve the patients' optimal health. Nevertheless, many people living with rheumatological diseases report disabilities, pain and fatigue, the disease impacts on daily life and activities [18]. Improving sexual health is complex and includes more than guidance about sexual activities when living with a chronic disease. Sexual health can be improved by interventions initiated and performed by various professionals for persons with chronic conditions, such as rheumatological diseases [5] [19] [20], but there are still difficulties in addressing and promoting sexual health in practice [21] [22] [23] [24]. Self-management strategies can also play an important role regarding sexual health for persons living with rheuma- 
tological diseases [4] [25], indicating the importance of involving the patient in the co-creation of health care services regarding sexual health. The current state, with insufficiently met sexual health care needs among patients with rheumatological diseases [25] [26] [27] shows the need to bring patients and professionals together in co-creatively exploring how to improve sexual health when living with rheumatological diseases. Co-creation can be described as a collaborative, generative, exploratory process, where professionals and academics work together with stakeholders to improve health services [28].

\section{Aim}

To co-create a working model aiming at improving sexual health for persons living with rheumatological diseases, that can be used by rheumatological teams in regular rheumatology practice.

\section{Method}

To create a working model this project has applied a co-creation design [28] since processes of co-creation may lead to unexpected insights regarding health care needs and improvement of health care services, and the knowledge is generated within the planned context of application [28] [29] [30].

Co-creative research includes three key features: 1) a systems perspective with emergent multiple interactive entities, which generate an outcome which is not fully predicted in advance; 2 ) the research process is viewed as a creative endeavour with strong links to design, while human imagination and the individual experience of patient and staff is at the core of the creative design effort; 3 ) the process of the co-creative efforts is as important as the generated product [28]. In co-creative research the role of diverse actors is recognized together with the benefit of integrating their unique knowledge and skills, by offering an approach and set of tools for collaboratively creating value through creative, participatory methods. Diversity within the research group regarding lived experience, professional experience and research experience was essential for the project. In addition, the research group, as well as the stakeholders, came from different clinics, thus providing broad perspectives on the explored topic. The co-creative process of the project has been performed in solidarity and negotiated participation, with patients and professionals being invited to share their views on the project throughout the process. Co-creative activities were performed with stakeholders throughout the process of developing the working model.

Equality in the relationships both within the research group and between stakeholders and the research group has been a key focus, together with the practical focus of the project.

\subsection{Participants}

Active stakeholder participation has been an important element of the research project throughout the process, with a patient representative as a full member of 
the research group, a researcher/clinician also being a patient and with stakeholders sharing their knowledge in advisory groups. The recruitment of stakeholders was attained through active information processes for both patients and professionals. A representative from the Swedish Rheumatism Association, a patient organization, was involved in recruiting persons wanting to be part of the advisory group. To increase interest in participation from professionals, information was given to managers by persons working both as researchers and clinicians, and also by a patient representative. It was also given directly by clinicians to other clinicians in various professions. Professionals from various professions and clinics opted to participate in the advisory group, and the following professions were represented: rheumatologist, nurse, physiotherapist, occupational therapist, and counsellor. When recruiting to the advisory groups, stakeholders were able to choose how and to what extent they wanted to participate in the research process. The participants in the patients' advisory group had to have lived experience of being diagnosed with a rheumatological disease, an interest in improving care. They also had to be positive towards discussing the topic of sexual health and older than 18. No individual data was collected from the stakeholders. During the work process the participants in advisory groups were given feedback on the on-going work and given the opportunity to provide further recommendations and information to the research group on several occasions during the process. The feedback opportunity and the ability for the advisory groups to follow the progress of the project are important but often missed steps in health care research [31]. The feedback from the advisory group in each of the steps in the co-creative process was analysed by the research group and changes in the working model were presented to the advisory group to ensure that changes were in line with what the advisory groups intended.

\subsection{Informed Consent}

Informed consent was obtained from all individual participants included in the study.

\subsection{Work Process}

The continuous development the research process, where the process could evolve and adapt according to the co-creative research design, is described together with the developmental steps of the model (Table 1). In the work process the patient advisory group were included prior to the professionals to gain insight into how patients preferred the working process prior to involving professionals. The advisory group activities structure was decided by the participating stakeholders.

\section{Results: A Model for Improving Sexual Health in Rheumatological Care}

The versions of the model followed a pattern, where the first version of the model was based on existing research and evidence-based practice, and the clinical 
Table 1. Work process of developing a co-created working model for improving sexual health in rheumatological care.

\begin{tabular}{|c|c|c|c|c|c|}
\hline & Work process & Activity & Participants & Steps & Content \\
\hline 1 & $\begin{array}{l}\text { Study design } \\
\text { \& planning, }\end{array}$ & $\begin{array}{l}\text { The co-creative process started } \\
\text { with a research group being set } \\
\text { up with representatives from } \\
\text { various professions in the } \\
\text { rheumatological team } \\
\text { (rheumatologist, occupational } \\
\text { therapist, physiotherapist, } \\
\text { social counsellor) and a patient } \\
\text { partner }\end{array}$ & $\begin{array}{l}\text { Research group } \\
\text { (researchers/ } \\
\text { clinicians/patient } \\
\text { partner) }\end{array}$ & $\begin{array}{l}\text { The research group decided how } \\
\text { to address the research question, } \\
\text { which included to present the } \\
\text { suggested plan to the patient } \\
\text { organization to assess the } \\
\text { relevance of the project for } \\
\text { persons living with } \\
\text { rheumatological diseases. }\end{array}$ & $\begin{array}{l}\text { After approval of the patient } \\
\text { organization, a preliminary } \\
\text { advisory group of patients was } \\
\text { formed, by advertising through } \\
\text { the national patient organization } \\
\text { and their regional branches }\end{array}$ \\
\hline 2 & $\begin{array}{l}\text { Study design } \\
\text { \& planning }\end{array}$ & $\begin{array}{l}\text { Establishing patient advisory } \\
\text { group by the patient } \\
\text { organizations webpage, social } \\
\text { media and e-mail to members } \\
\text { in the organization living in the } \\
\text { area. In addition, related } \\
\text { organizations were contacted } \\
\text { such as the association for } \\
\text { young persons living with } \\
\text { rheumatological diseases, to } \\
\text { facilitate a broader sample with } \\
\text { a wide range of experience in } \\
\text { the reference group }\end{array}$ & $\begin{array}{l}\text { Patient partner and } \\
\text { patient advisory } \\
\text { group }\end{array}$ & $\begin{array}{l}\text { The advisory group of patients } \\
\text { gained information about the } \\
\text { aim of the study and the } \\
\text { suggested role of the stakeholder } \\
\text { advisory groups by obtaining } \\
\text { written and oral information } \\
\text { from the patient partner. }\end{array}$ & $\begin{array}{l}\text { The patients preferred the } \\
\text { patients and the professionals to } \\
\text { have different advisory groups } \\
\text { due to the topic }\end{array}$ \\
\hline 3 & $\begin{array}{l}\text { Study design } \\
\text { \& model } \\
\text { development }\end{array}$ & $\begin{array}{l}\text { Meeting with advisory group of } \\
\text { patients }\end{array}$ & $\begin{array}{l}\text { Patient partner, } \\
\text { researcher/clinician } \\
\text { and patient advisory } \\
\text { group }\end{array}$ & $\begin{array}{l}\text { A meeting including a brief } \\
\text { introduction to the concept of } \\
\text { sexual health, thereafter having } \\
\text { the opportunity to discuss the } \\
\text { aim of this study and give } \\
\text { recommendations on if/how the } \\
\text { study should continue. }\end{array}$ & $\begin{array}{l}\text { The advisory group was positive } \\
\text { towards the aim of the study and } \\
\text { gave suggestions for important } \\
\text { areas of living with } \\
\text { rheumatological diseases and } \\
\text { sexual health that should be } \\
\text { considered in the model. The } \\
\text { advisory group also opted to give } \\
\text { additional responses and } \\
\text { suggestions by e-mail. }\end{array}$ \\
\hline 4 & $\begin{array}{c}\text { Study } \\
\text { design \& model } \\
\text { development }\end{array}$ & Research group work & Research group & $\begin{array}{l}\text { Suggestions from the patient } \\
\text { advisory group added to an } \\
\text { explorative understanding of the } \\
\text { topic, together with prior } \\
\text { research in the field and } \\
\text { sharing of knowledge enabled } \\
\text { the first version of the working } \\
\text { model. }\end{array}$ & $\begin{array}{l}\text { A first version of the working } \\
\text { model }\end{array}$ \\
\hline 5 & $\begin{array}{c}\text { Model } \\
\text { development }\end{array}$ & $\begin{array}{l}\text { E-mail correspondence } \\
\text { presenting the first version of } \\
\text { the working model }\end{array}$ & $\begin{array}{l}\text { Patient partner and } \\
\text { patient advisory } \\
\text { group }\end{array}$ & $\begin{array}{l}\text { The first version of the working } \\
\text { model was sent to the patients' } \\
\text { advisory group for responses } \\
\text { and suggestions }\end{array}$ & $\begin{array}{l}\text { Additional comments led to a } \\
\text { revision by the research group of } \\
\text { the working model (second } \\
\text { version) }\end{array}$ \\
\hline 6 & $\begin{array}{c}\text { Study } \\
\text { design \& model } \\
\text { development }\end{array}$ & $\begin{array}{l}\text { Additional patients opted in } \\
\text { and were included to } \\
\text { participate in the project as } \\
\text { advisory group participants, } \\
\text { due to interest in the topic }\end{array}$ & $\begin{array}{l}\text { Patient partner and } \\
\text { patient advisory } \\
\text { group }\end{array}$ & $\begin{array}{l}\text { The additional patients were } \\
\text { included in the patients' } \\
\text { advisory group and the first } \\
\text { version of the working model } \\
\text { was sent to the patients' advisory } \\
\text { group by e-mail for responses } \\
\text { and suggestions }\end{array}$ & $\begin{array}{l}\text { Additional comments led to a } \\
\text { revision by the research group of } \\
\text { the working model (third } \\
\text { version) }\end{array}$ \\
\hline
\end{tabular}




\section{Continued}

$7 \quad$ Study design

8

Model development

Model development

Model development
Establishing a reference group
of professionals

Oral and written information about the study was sent to clinical managers of rheumatological teams at two regional centres to recruit professionals.
Two reference groups of professionals (The advisory groups included the following professions: nurse, rheumatologist, physiotherapist, occupational therapist, counsellor) were formed through a convenience sample of professionals from two regional centres of rheumatological teams. The division into two groups based on working location was chosen to minimize time off work in accordance with requests from the professionals

A meeting including an introduction to the study, a brief

Patient partner, introduction to the concept of Meeting with advisory group of researcher/clinician sexual health, and discussion of professionals $1 \quad$ and professionals' advisory group

the third version of the working model and how this model could be applicable in clinical practice from their professional view

A meeting including an introduction to the study, a brief introduction to the concept of Researcher/clinician sexual health and discussion of Meeting with advisory group of and professionals' the fourth version of the working model and how this model could be applicable in clinical practice from their professional view

The fourth version of the E-mail correspondence Patir presenting the fourt Patient partner and working model was sent to the the working model volunteering patients patients' advisory group for responses and suggestions

Creation of learning material

Finalizing model

11 and developing Research group meeting learning material

Research group based on the work process and the working model

Researcher and Testing the learning material in patient organization a specific context

Continuous development of learning material and testing of the working model
Revision by the research group version)

The group suggested learning material as an addition to the working model to facilitate implementation of the working model in clinical practice

No additional revisions suggested. The patient advisory group concluded that they preferred to contribute at the beginning of the project rather than on the more finalized product.

Finalizing the working model (see Table 2)

Need of adaption of learning material in accordance to context for various groups of the working model (fourth
Spreading the results of the study
Research group and users

experience of the research group together with perspectives from stakeholders. In the first version, the focus of the working model was existing research on treatment of sexual health dysfunction in general and recommendations for 
rheumatological rehabilitation. The second version of the working model was more detailed, concerning areas of responsibility for the team, the professional and the patient. The third version of the working model was revised to further enhance the agreement on the content of the model by the advisory groups and the research group. In addition, findings regarding suggested needs for support were listed. This support was considered essential for enabling use of the working model in clinical practice. In the fourth and final model the concept of how each person in the working model (the patient, the professionals, the team) could support other participants in the working model was incorporated, thus defining both the role of giving support as well as being in need of support for all actors, to optimize sexual health for persons living with rheumatological diseases (Table 2).

\subsection{The Role of the Patient in the Working Model to Improve Sexual Health}

The role of the patient is an active role, and involves deciding on what personal information to share and what kind of support is of interest. The patient needs to be clear on what the problem is, what support he/she is presently asking for, what he/she wants to change and what his/her expectations are. It is also the patient who choses what information he/she is willing to share regarding his/her sexual life. It is recommended that patients reflect upon those issues prior to a healthcare visit. The patient is also encouraged to prepare their partner prior to visits to the rheumatological team if the patient wishes to discuss sexual health

Table 2. The working model including key components of participants acting to improve sexual health in the rheumatological team.

\begin{tabular}{|c|c|c|}
\hline \multicolumn{3}{|c|}{ Improving sexual health with shared information, knowledge and responsibility } \\
\hline Pati & Professionals & Tea \\
\hline \multicolumn{3}{|c|}{ Needing support and being supportive } \\
\hline $\begin{array}{l}\text { What is the information } \\
\text { about your sexual health } \\
\text { that you are willing to } \\
\text { share, and what are your } \\
\text { expectations and what kind } \\
\text { of support do you request? } \\
\text { - What information do you } \\
\text { want to/can you give the } \\
\text { team and the professionals } \\
\text { to enable them to give you } \\
\text { the best possible support? } \\
\text { If you want your partner to } \\
\text { be involved in } \\
\text { communication about } \\
\text { sexual health, give the } \\
\text { partner the same } \\
\text { opportunity as yourself to } \\
\text { prepare for the meeting }\end{array}$ & $\begin{array}{l}\text { Recognize all individuals' right } \\
\text { to sexual and reproductive } \\
\text { health and its importance for } \\
\text { general well-being } \\
\text { - Use professional knowledge to } \\
\text { promote sexual health } \\
\text { - Be up-to-date and use your } \\
\text { professional competence } \\
\text { concerning research and } \\
\text { development in sexual health in } \\
\text { your profession } \\
\text { Regularly follow-up the } \\
\text { individual's needs concerning } \\
\text { sexual health and how the } \\
\text { disease affects sexual health, } \\
\text { using general information and } \\
\text { questions }\end{array}$ & $\begin{array}{l}\text { - Clarify the shared } \\
\text { responsibility of the team } \\
\text { members concerning } \\
\text { promotion of sexual health in } \\
\text { their professional roles } \\
\text { - Be open to communication } \\
\text { with patients about sexual } \\
\text { health } \\
\text { - Understand that sexual health } \\
\text { is a broader concept than } \\
\text { sexual function and } \\
\text { reproduction } \\
\text { - Ensure competence in sexual } \\
\text { health and rheumatological } \\
\text { disease within the team } \\
\text { - Share up-to-date, correct and } \\
\text { person-adapted information } \\
\text { - Have knowledge about } \\
\text { possibilities for further referral }\end{array}$ \\
\hline
\end{tabular}


with their partner present. This is to enable the partner to have reflected on his/her integrity and willingness to share information regarding the couple's sexual health. Having reflected on and being precise about those issues helps health care professionals and may be necessary to enable them to support the patient. The needed support for the patient is as follows: health care professionals/the team should take the initiative to discuss sexual health; should show understanding that sexual health is a broader concept than just sexual function; should support and confirm sexual health through openness to discussing the disease impact on sexual health; and should give correct information and time for questions-also for the partner if present. Professionals/the team also need to consider the patient's context, where the patient is in the disease progress, how sexual health can be affected at that stage, and what type of support is currently needed. Early information is important but needs to be adapted to context.

\subsection{The Role of the Professional in the Working Model to Improve Sexual Health}

The role of the professional could be described as key points to consider for each profession, to ensure that each profession's specific knowledge and capacity is used to promote sexual health as well as general health, well-being and quality of life. The role of the professional is also to initiate and enable conversations regarding sexual health, disease impact and treatment impact on sexual health, and to provide up-to-date, evidence-based information to share, information that meets the person's needs, and if necessary the partner's needs. Firstly, the professional needs to recognize the patient's sexual and reproductive health and rights; secondly, the professional must use his/her professional competence to improve sexual health by supporting and assisting in solving problems related to decreased sexual health related to rheumatological diseases or treatment. Enabling conversations about sexual health includes being open, listening and being supportive, despite the sensitive and personal topic. To ensure they can support patients each professional has a responsibility to be up to date with new research in their professions also regarding sexual health connected to rheumatological diseases. Thereafter, the professional needs to continuously follow-up sexual health when meeting the patient by providing appropriate information (preferably both oral and written information) and asking questions appropriate to the patient's context and disease progression (the recommendation is to use checklists and routine questions). Patients prefer more general questions, rather than detailed questions, with clarifications of what common sexual health issues are and what can be considered as disease-specific sexual health issues. Patients also need information about potential solutions and lifestyle changes that may improve sexual health. To support the patient's sexual health there is a need to help professionals with competence development regarding sexual health and communication models (such as Ex-PLISSIT [32] [33] and the Recognition Model [34]) and to provide documentation on sexual health. Communication models can work as enablers for initiating conversations on sensitive topics, such as 
sexual health issues [32] [33] [34]. Each profession in the rheumatological team has specific professional expertise that can promote sexual health. Examples of professional support from professions engaged in rheumatological care are;

Rheumatologists: Information on how diagnosis and medications can affect sexual desire, sexual satisfaction and reproduction, and when needed they can provide medication to promote sexual health.

Nurses: Support information given by rheumatologists concerning medication and how it may affect sexual health, and also provide the possibility for patients and partners to ask questions and gain knowledge regarding sexual health and reproduction.

Occupational therapists: Provide information concerning sexual aids and assist in planning of valued life activities, including sexual activities.

Physiotherapists: Provide information regarding physical activity and its positive effect on sexual health, as well as regarding sexual positions that are less strenuous on painful/replaced joints.

Counsellor: Being supportive and presenting a safe environment for communication about sexual health and intimate relationships to assist in decreasing stress and creating energy for the relationship.

\subsection{The Role of the Team in the Working Model to Improve Sexual Health}

The team refers to the group of professionals that work together at a clinic to improve health for persons living with rheumatological diseases; therefore, the composition of the team may vary in various contexts. Considering the important role of professional teamwork in rheumatological care, how the team members communicate and work together can also play an important role in promoting sexual health. The role of the team in sexual health includes a collaborative understanding and shared competence, together with implementing a shared strategy on how to work together to promote sexual health for persons with rheumatological diseases. The importance of the team is connected to the organizational culture, where the team plays an important role in fostering a positive climate towards promoting sexual health for persons living with rheumatological diseases. Therefore, the team needs to follow these basic principles:

- Ensure openness towards professional communication concerning sexual health-within the team and to enable conversations/information for patients and partners.

- Present an understanding within the team that sexual health is a broad and complex concept, covering more than sexual function and reproduction.

- Ensure the team's competence and continuous updating of competence regarding sexual health and disease impact on sexual health.

- Provide updated, correct and personalized information for patients and their partners.

- Clarify the shared responsibility of the team members concerning promotion of sexual health in their professional roles. 
There are activities that can assist in promoting sexual health such as shared professional visits/team visits, referral to other health care services concerning sexual health issues not related to rheumatological diseases or treatment. The mentioned strategies for the rheumatological team are dependent on support from managers to include sexual health in ordinary care and to support an organizational culture that promotes sexual health.

\section{Discussion}

This co-created working model is intended to assist in optimizing sexual health for patients living with rheumatological diseases, by self-management through shared knowledge, but also by professionals addressing and caring for sexual health using their professional expertise. The working model includes the supportive role for each participant in both giving and receiving support to enable promotion of sexual health for persons living with rheumatological diseases. In the ground rules for co-creation it is important to define early who is responsible for what and to whom [28] [35], which is a focus of the described model for sexual health. The model also emphasises that professionals can rely on their existing skills to enhance sexual health, which has been shown in previous research [34]. The results in this study present co-created knowledge, which can be useful in rheumatological care for the individual patient, for professionals and for teams. The results can be seen as an important contribution to previous research presenting how specific professions can contribute to promoting sexual health for persons living with rheumatological diseases [5] [20] [36]. The model can assist in clarifying difficulties in functioning affecting sexual health and how to best address them. However, the presented working model also provides additional understanding of needed support, and the necessity of co-creation and knowledge-sharing within the team and with the patient to enable continuous promotion of sexual health and rehabilitation of sexual health for persons living with rheumatological diseases. To enable professionals to use their professional knowledge to promote sexual health it is evident that additional competence and support are needed, especially since research has shown several barriers to health care professionals concerning addressing sexual health and the patients' need for support regarding sexual health issues [8] [37]. During the development of the model the need for support became evident, and in the process both professionals and patients acknowledged their ability to give support as well as their need for support. The need for support concerned competence development, structures and routines for sharing information, and managerial support for including sexual health in rheumatological care. The shared learning concerning the need of support to and from patients, professionals and the team is an important added value of the research project, which was enabled by the co-creative work process, and it could be useful in developing rheumatological care.

The use of co-creation in healthcare can lead to different, and sometimes unexpected forms of knowledge, exploration of values and social relations, creating 
user-led health care services [29] [38], and during the work process in this project, it was clear how co-creation gave added insights and prompted the continuous improvement of the working model. Traditionally, when designing health care services, focus has been more on professional expertise and the professionals' way of designing a service, than on interactive service design through dialogue with patients in equal collaboration [39] [40] [41], and co-creating a service can be seen as a step away from the professional dominance of best practice in health service design. The co-creative process provided opportunities for additional learning and understanding of various stakeholders' roles. Another interesting finding in this study was that the patients participating in the advisory group, said that they were more interested in sharing their opinions at the beginning of the work process, where they found it important that their opinions were given attention and steered the development of the model, while they were less interested in commenting on a detailed level about the final model. This emphasizes the importance of including patients at the start of research and development projects and of giving them equal opportunities, as professionals and researchers in planning the project.

The value of co-creation has been considered key when working towards creating a useful working model for rheumatological teams to address sexual health and meet the needs of persons living with rheumatological diseases in this field. To evaluate the product of the project, the working model, additional testing in clinical practice is needed. To ensure the pragmatic usefulness of the working model and its learning material the next step is to test the model in clinical practice. The tests will evaluate the pragmatic use of the model as a tool to improve sexual health for persons living with rheumatological diseases. During the process of developing the model the research group has had dialogues concerning the working model with stakeholders at professional gatherings and in professional education activities, which has been valuable in the development of learning materials connected to the model. At such meetings there has been both an interest in the model, but also an interest in developing clinical routines connected to sexual health in rheumatology. However, tests of the model need to be performed in various contexts over time to ensure a sustainable outcome, and because context is of importance regarding sexual health [14]. The working model can also be used by individual patients, professionals and teams as a basis for reflection on their own knowledge and actions concerning meeting the needs and promoting sexual health for persons living with rheumatological diseases. The working model could be useful for other chronic diseases, since the focus is on generic strategies and support of sexual health. Further research is recommended to test the usefulness of the model in various populations and contexts. The possible utility of the model for other populations is enhanced by the co-creative research design, which enables the nuances of the specific setting and context of health experiences to develop to transferable patient-centred knowledge that can be applied elsewhere [38]. 


\section{Methodological Discussion}

The co-creative research includes three key features which have been challenging and inspiring in this study, where the results were concerned more with the development of a learning tool and generation of knowledge about the needs and abilities of each stakeholder to enable improvement of sexual health, more than simply with producing a working tool for professionals. The usefulness of the working model has been enhanced by the co-creative process in which it was developed, since stakeholders' perspectives were an active and equal part of the development process. Co-creation of research can bring challenges, particularly because it is not always compatible with traditional academic research and expectations on research [38]. Flexibility in the research approach was essential in the process of this study, for example physical meetings were not always possible to organize with all stakeholders at once; instead other spaces for dialogue that better met participants' needs and preferences were used. In another collaborative method, the Delphi method, participants are requested to commit to participating throughout the project according to the Delphi procedure [42], while the flexibility in this project allowed stakeholders to choose to what extent they participated. The continuous dialogue between the research group and the advisory groups through the research project was valuable, and was in line with previous research emphasizing the need for reciprocal relationships between researchers and stakeholders to obtain the best possible outcome [31]. In this perspective the diversity of the research group was also seen as giving additional value, since the perspectives of the professional, the patient and the researcher were personally presented in all steps of the research process. The necessity of all participants being active research partners through the research process, even if it may be more time-consuming and challenging, has been reported in previous co-creation research and is considered vital to enable collective sense-making and negotiation to create new understandings [28] [30] [38] [41]. The learning process of the research group has been a great advantage of the study design, since the learning journey has not only led to learning but also to a deeper understanding of key learning components regarding how to include sexual health in rheumatology care, and the barriers and facilitators that may be present in various contexts. To share the learning process the study has also led to the design of a learning tool to enhance the usefulness of the working model for both professionals and persons living with rheumatological diseases. Reflecting on our own roles in the research process and how they shape our work has helped us criticise our own assumptions throughout the process and has increased our knowledge generation in the project and the development of the model. Thus, we as authors agree that the process of the co-creative research effort is as important as the generated product of this study. However, the co-creative research design was novel to the research group, which may have increased the timespan of the project, but also may have led to added knowledge of both the methodology and the studied topic. 


\section{Conclusions}

The co-creative work process identified crucial factors concerning promoting sexual health for persons living with rheumatological diseases, resulting in a working model for patients, professionals and multi-professional teams. The model includes the support needed from and to each participant in the process of promoting sexual health, while remaining within the professional scope of the professionals' knowledge and capacity, and in line with the needs of the persons living with rheumatological diseases.

Co-creation was experienced to be a useful research model to improve rheumatological care, through valuing and using the competence of all research members equally.

\section{Funding}

The study was funded by the Medical Research Council of Southeast Sweden, grant number FORSS701251.

\section{Conflicts of Interest}

The authors declare no conflicts of interest regarding the publication of this paper.

\section{References}

[1] (2018) UngaReumatiker: Vi är inte vår sjukdom. Unga Reuamtiker-Rapporten 2018.

[2] Ostensen, M. (2017) Sexual and Reproductive Health in Rheumatic Disease. Nature Reviews Rheumatology, 13, 485-493. https://doi.org/10.1038/nrrheum.2017.102

[3] Strand, V. and Singh, J.A. (2017) Patient Burden of Axial Spondyloarthritis. JCR: Journal of Clinical Rheumatology, 23, 383-391. https://doi.org/10.1097/RHU.0000000000000589

[4] Helland, Y., Kjeken, I., Steen, E., Kvien, T.K., Hauge, M.I. and Dagfinrud, H. (2011) Rheumatic Diseases and Sexuality: Disease Impact and Self Management Strategies. Arthritis Care \& Research (Hoboken), 63, 743-750. https://doi.org/10.1002/acr.20424

[5] Żuk, B. and Maślińska, M. (2017) The Importance of Physiotherapy in the Sexuality of Patients with Rheumatic Diseases. Reumatologia, 55, 237-241. https://doi.org/10.5114/reum.2017.71640

[6] Dorner, T.E., Berner, C., Haider, S., Grabovac, I., Lamprecht, T., Fenzl, K.H. and Erlacher, L. (2018) Sexual Health in Patients with Rheumatoid Arthritis and the Association between Physical Fitness and Sexual Function: A Cross-Sectional Study. Rheumatology International, 38, 1103-1114. https://doi.org/10.1007/s00296-018-4023-3

[7] Kobelt, G., Woronoff, A.S., Bertholon, D.R., Texier-Richard, B., Gaigi, H., Perdriger, A., Maugars, Y., Combe, B. and Mimoun, S. (2010) Sexuality and Relationship in Patients with Rheumatoid Arthritis in France. Annals of the Rheumatic Diseases, 69, 358.

[8] Orzúa-de la Fuente, W.M., Salazar-Hernández, G.J., Vega-Morales, D., Garza-Alpírez, A. and Esquivel-Valerio, J.A. (2018) High Prevalence of Sexual Dysfunction in Women with Rheumatic Diseases: A Not Recognized Health Domain. Sex- 
uality \& Disability, 36, 407-416. https://doi.org/10.1007/s11195-018-9542-Z

[9] Anastasiadis, A.G., Davis, A.R., Ghafar, M.A., Burchardt, M. and Shabsigh, R. (2002) The Epidemiology and Definition of Female Sexual Disorders. World Journal of Urology, 20, 74-78. https://doi.org/10.1007/s00345-002-0272-5

[10] Davison, S.L., Bell, R.J., LaChina, M., Holden, S.L. and Davis, S.R. (2009) The Relationship between Self-Reported Sexual Satisfaction and General Well-Being in Women. The Journal of Sexual Medicine, 6, 2690-2697. https://doi.org/10.1111/j.1743-6109.2009.01406.x

[11] Diamond, L.M. and Huebner, D.M. (2012) Is Good Sex Good for You? Rethinking Sexuality and Health. Social and Personality Psychology Compass, 6, 54-69. https://doi.org/10.1111/j.1751-9004.2011.00408.x

[12] Lamont, J. (2012) Female Sexual Health Consensus Clinical Guidelines. Journal of Obstetrics and Gynaecology Canada: JOGC, 34, 769-775. https://doi.org/10.1016/S1701-2163(16)35341-5

[13] Moin, V., Duvdevany, I. and Mazor, D. (2009) Sexual Identity, Body Image, and Life Satisfaction among Women with and without Physical Disability. Sexuality and Disability, 27, 83-95. https://doi.org/10.1007/s11195-009-9112-5

[14] Atallah, S., Johnson-Agbakwu, C., Rosenbaum, T., Abdo, C., Byers, E.S., Graham, C., Nobre, P., Wylie, K. and Brotto, L. (2016) Ethical and Sociocultural Aspects of Sexual Function and Dysfunction in Both Sexes. The Journal of Sexual Medicine, 13, 591-606. https://doi.org/10.1016/j.jsxm.2016.01.021

[15] Althof, S.E., Rosen, R.C., Perelman, M.A. and Rubio-Aurioles, E. (2013) Standard Operating Procedures for Taking a Sexual History. The Journal of Sexual Medicine, 10, 26-35. https://doi.org/10.1111/j.1743-6109.2012.02823.x

[16] Palmer, D. and El Miedany, Y. (2011) Sexual Dysfunction in Rheumatoid Arthritis: A Hot But Sensitive Issue. British Journal of Nursing, 20, 1134-1137. https://doi.org/10.12968/bjon.2011.20.17.1134

[17] Georgopoulou, S., Prothero, L. and D’Cruz, D.P. (2018) Physician-Patient Communication in Rheumatology: A Systematic Review. Rheumatology International, 38, 763-775. https://doi.org/10.1007/s00296-018-4016-2

[18] Al Maini, M., Adelowo, F., Al Saleh, J., Al Weshahi, Y., Burmester, G.-R., Cutolo, M., Flood, J., March, L., McDonald-Blumer, H., Pile, K., Pineda, C., Thorne, C. and Kvien, T.K. (2015) The Global Challenges and Opportunities in the Practice of Rheumatology: White Paper by the World Forum on Rheumatic and Musculoskeletal Diseases. Clinical Rheumatology, 34, 819-829. https://doi.org/10.1007/s10067-014-2841-6

[19] Areskoug-Josefsson, K. and Gard, G. (2015) Physiotherapy as a Promoter of Sexual Health. Physiotherapy Theory and Practice, 31, 390-395.

[20] Almeida, P.H., Castro Ferreira, C., Kurizky, P.S., Muniz, L.F. and Mota, L.M. (2015) How the Rheumatologist Can Guide the Patient with Rheumatoid Arthritis on Sexual Function. Revista Brasileira de Reumatologia, 55, 458-463. https://doi.org/10.1016/j.rbre.2014.08.008

[21] McGrath, M. and Sakellariou, D. (2016) Why Has So Little Progress Been Made in the Practice of Occupational Therapy in Relation to Sexuality? American Journal of Occupational Therapy, 70, 1-5. https://doi.org/10.5014/ajot.2016.017707

[22] Areskoug-Josefsson, K. and Oberg, U. (2009) A Literature Review of the Sexual Health of Women with Rheumatoid Arthritis. Musculoskeletal Care, 7, 219-226. https://doi.org/10.1002/msc.152

[23] Areskoug Josefsson, K. and Öberg, U. (2011) Sexual Health and Intimate Relation- 
ships in Rheumatoid Arthritis. In: Lemmey, A.B., Ed., Rheumatoid Arthritis, Etiology, Consequences and Co-Morbidities, InTech, Rijeka, 215-234. https://doi.org/10.5772/25861

[24] Josefsson, K.A. and Gard, G. (2012) Sexual Health in Patients with Rheumatoid Arthritis: Experiences, Needs and Communication with Health Care Professionals. Musculoskeletal Care, 10, 76-89. https://doi.org/10.1002/msc.1002

[25] Ostlund, G., Bjork, M., Valtersson, E. and Sverker, A. (2015) Lived Experiences of Sex Life Difficulties in Men and Women with Early RA-The Swedish TIRA Project. Musculoskeletal Care, 13, 248-257. https://doi.org/10.1002/msc.1105

[26] Helland, Y., Dagfinrud, H., Haugen, M.I., Kjeken, I. and Zangi, H. (2017) Patients' Perspectives on Information and Communication about Sexual and Relational Issues in Rheumatology Health Care. Musculoskeletal Care, 15, 131-139.

https://doi.org/10.1002/msc.1149

[27] Josefsson, K.A. and Gard, G. (2010) Women's Experiences of Sexual Health When Living with Rheumatoid Arthritis-An Explorative Qualitative Study. BMC Musculoskeletal Disorders, 11, Article No. 240. https://doi.org/10.1186/1471-2474-11-240

[28] Greenhalgh, T., Jackson, C., Shaw, S. and Janamian, T. (2016) Achieving Research Impact through Co-Creation in Community-Based Health Services: Literature Review and Case Study. The Milbank Quarterly, 94, 392-429. https://doi.org/10.1111/1468-0009.12197

[29] Filipe, A., Renedo, A. and Marston, C. (2017) The Co-Production of What? Knowledge, Values, and Social Relations in Health Care. PLOS Biology, 15, e2001403. https://doi.org/10.1371/journal.pbio.2001403

[30] Liabo, K., Boddy, K., Burchmore, H., Cockcroft, E. and Britten, N. (2018) Clarifying the Roles of Patients in Research. BMJ, 361, k1463. https://doi.org/10.1136/bmj.k1463

[31] Mathie, E., Wythe, H., Munday, D., Millac, P., Rhodes, G., Roberts, N., Smeeton, N., Poland, F. and Jones, J.G. (2018) Reciprocal Relationships and the Importance of Feedback in Patient and Public Involvement: A Mixed Methods Study. Health EXpectations, 21, 899-908. https://doi.org/10.1111/hex.12684

[32] Taylor, B. and Davis, S. (2006) Using the Extended PLISSIT Model to Address Sexual Healthcare Needs. Nursing Standard, 21, 35-40. https://doi.org/10.7748/ns.21.11.35.s52

[33] Taylor, B. and Davis, S. (2007) The Extended PLISSIT Model for Addressing the Sexual Wellbeing of Individuals with an Acquired Disability or Chronic Illness. Sexuality and Disability, 25, 135-139. https://doi.org/10.1007/s11195-007-9044-x

[34] Couldrick, L., Gaynor, S. and Cross, V. (2010) Proposing a New Sexual Health Model of Practice for Disability Teams: The Recognition Model. International Journal of Therapy and Rehabilitation, 17, 290-298. https://doi.org/10.12968/ijtr.2010.17.6.48152

[35] Boudes, M., Robinson, P., Bertelsen, N., Brooke, N., Hoos, A., Boutin, M., Geissler, J. and Sargeant, I. (2018) What Do Stakeholders Expect from Patient Engagement: Are These Expectations Being Met? Health Expectations, 26, 1035-1045. https://doi.org/10.1111/hex.12797

[36] Ryan, S. and Wylie, E. (2005) An Exploratory Survey of the Practice of Rheumatology Nurses Addressing the Sexuality of Patients with Rheumatoid Arthritis. Musculoskeletal Care, 3, 44-53. https://doi.org/10.1002/msc.25

[37] Helland, Y., Garratt, A., Kjeken, I., Kvien, T.K. and Dagfinrud, H. (2013) Current 
Practice and Barriers to the Management of Sexual Issues in Rheumatology: Results of a Survey of Health Professionals. Scandinavian Journal of Rheumatology, 42, 20-26. https://doi.org/10.3109/03009742.2012.709274

[38] Miles, S., Renedo, A. and Marston, C. (2018) "Slow Co-Production" for Deeper Patient Involvement in Health Care. The Journal of Health Design, 3, 57-62.

https://doi.org/10.21853/JHD.2018.39

[39] Vamstad, J. (2015) Co-Production of Childcare and Addiction Treatment in Sweden: The Same Co-Production in Very Different Service Areas? Polityka Spoleczna, 11, 15-50.

[40] Jiwa, M. (2018) How Patients Can Improve Health Care. The Journal of Health Design, 3, 47-48.

[41] Tritter, J.Q. (2009) Revolution or Evolution: The Challenges of Conceptualizing Patient and Public Involvement in a Consumerist World. Health Expectations. An International Journal of Public Participation in Health Care and Health Policy, 12, 275-287. https://doi.org/10.1111/j.1369-7625.2009.00564.x

[42] Boulkedid, R., Abdoul, H., Loustau, M., Sibony, O. and Alberti, C. (2011) Using and Reporting the Delphi Method for Selecting Healthcare Quality Indicators: A Systematic Review. PLoS ONE, 6, e20476. https://doi.org/10.1371/journal.pone.0020476 